\title{
Influência da porosidade em algumas propriedades mecânicas da liga de Al-6,5\%Si-0,6\%Mg fundida e tratada termicamente
}

\author{
Influence of porosity on some mechanical \\ properties of an $\mathrm{Al}-6.5 \% \mathrm{Si}-0.6 \% \mathrm{Mg}$ \\ as-cast and heat-treated alloy
}

Albino Moura Guterres ${ }^{1}$, Claudio André Lopes de Oliveira ${ }^{1}$, Carlos Alexandre dos Santos ${ }^{2}$

\footnotetext{
${ }^{1}$ Instituto Federal Sul-rio-grandense, Passo Fundo, Rio Grande do Sul, Brasil.

${ }^{2}$ Pontifícia Universidade Católica do Rio Grande do Sul, Porto Alegre, Rio Grande do Sul, Brasil.

e-mail: albino.moura@passofundo.ifsul.edu.br, claudio.oliveira@passofundo.ifsul.edu.br, carlos.santos@pucrs.br
}

\begin{abstract}
RESUMO
As ligas de Al-Si-Mg são atualmente as mais utilizadas para obtenção de peças fundidas comerciais, isto porque as propriedades mecânicas desses materiais podem ser melhoradas através de tratamentos térmicos. No entanto, cabe salientar que nas peças fundidas de ligas de alumínio, a porosidade é o defeito que ocorre mais frequentemente. Esse defeito geralmente resulta em propriedades mecânicas pobres. Nesse sentido, o presente estudo tem como objetivo analisar a influência do percentual de porosidade nas propriedades mecânicas de limite de resistência à tração, deformação específica e dureza em uma liga de $\mathrm{Al}-\mathrm{Si}-\mathrm{Mg}$ fundida e tratada termicamente. Para tanto, foi obtida por processo de fundição e solidificação a liga Al-6,5\% Si-0,6\% Mg (\% em massa). A partir da liga básica foram obtidos lingotes com e sem processo de desgaseificação com pastilhas de hexacloroetano. Os lingotes produzidos foram submetidos a tratamentos térmicos de solubilização e posterior envelhecimento artificial. Amostras transversais foram extraídas ao longo do comprimento dos lingotes para análise do percentual de porosidade e determinação das propriedades mecânicas. Com os resultados determinados nas análises de porosidade e ensaios mecânicos de tração e dureza, foi determinada a influência do percentual de porosidade na variação das propriedades mecânicas.
\end{abstract}

Palavras-chave: Ligas Al-Si-Mg, Solubilização e envelhecimento, Porosidade, Propriedades Mecânicas.

\section{ABSTRACT}

$\mathrm{Al}-\mathrm{Si}-\mathrm{Mg}$ alloys are currently the most popular alloys for obtaining commercial castings, because the mechanical properties of these materials can be improved by heat treatments. However, it should be noted that in cast aluminum alloy parts, porosity is the most frequently occurred defect. This defect usually results in poor mechanical properties. In this sense, the present study aims to analyze the influence of the porosity fraction on the mechanical properties of ultimate tensile strength, specific deformation and hardness in as cast and thermally treated Al-Si-Mg alloy. For that, it was obtained by natural casting and solidification process, an alloy having the following chemical composition: Al-6.5\% Si-0.6\% Mg. From the basic alloy were obtained ingots with and without degasification process with hexachloroethane pellets. The ingots produced were subjected to thermal treatments of solubilization and subsequent artificial aging. Transverse samples were drawn along the length of the ingots for analysis of porosity fraction and determination of mechanical properties. With the results found in the analysis of porosity and the mechanical tests of tensile and hardness, it was measured the influence of the percentage of porosity on the variation of the mechanical properties.

Keywords: Al-Si-Mg alloys, Solubilization and aging, Porosity, Mechanical Properties.

\section{INTRODUÇÃO}

O uso de peças fundidas de alumínio na indústria aeronáutica, automotiva e em geral, tem aumentado drasticamente ao longo das últimas três décadas [1]. A excelente fluidez, os custos de produção relativamente bai- 
xos, e a alta resistência em relação ao peso fazem das ligas fundidas de $\mathrm{Al}-\mathrm{Si}-\mathrm{Mg}$ opções atraentes para uso em componentes de engenharia mais baratos e mais leves [2].

Na indústria automotiva se aposta no crescimento do uso de ligas de alumínio, pois o objetivo geral é reduzir ainda mais o consumo de combustível dos automóveis. O aspecto mais vantajoso da aplicação de componentes fundidos de alumínio nos veículos é a aplicação de peças de alta resistência com baixo peso, gerando menor gasto de combustível [3].

Conforme KAELL [4], o sistema de ligas alumínio - silício é um dos mais importantes para a indústria de fundição, principalmente devido a sua alta fluidez conferida pela presença do eutético AlSi. A adição de magnésio torna as ligas tratáveis termicamente. Desta forma, as ligas de $\mathrm{Al}-\mathrm{Si}-\mathrm{Mg}$ são atualmente as mais populares para obtenção de peças fundidas comerciais. Dois importantes membros desta família de liga são as ligas 356.0 e 357.0 (designações de ligas da Aluminum Association) e para essas ligas a Aluminum Association [5] especifica as composições químicas, descritas na Tabela 1.

Tabela 1: Composições químicas das ligas 356.0 e 357.0 de acordo com a Aluminum Association [5].

Limites máximos e faixas para composição química (\% em massa)

\begin{tabular}{c|c|c|c|c|c|c|c|c}
\hline Liga & $\mathrm{Si}$ & $\mathrm{Fe}$ & $\mathrm{Cu}$ & $\mathrm{Mn}$ & $\mathrm{Mg}$ & $\mathrm{Zn}$ & $\mathrm{Ti}$ & Outros \\
\hline 356.0 & $6,5-7,5$ & 0,60 & 0,25 & 0,35 & $0,2-0,45$ & 0,35 & 0,25 & 0,15 \\
\hline 357.0 & $6,5-7,5$ & 0,15 & 0,05 & 0,03 & $0,45-0,6$ & 0,05 & 0,2 & 0,15 \\
\hline
\end{tabular}

Fonte: ASM Handbook Casting [5].

As propriedades mecânicas dessas ligas solidificadas em coquilhas e tratadas termicamente com tratamento térmico T6 (tratamento térmico de endurecimento por precipitação), são especificadas pela norma ASTM B 108 [6], conforme a Tabela 2.

Tabela 2: Propriedades mecânicas mínimas para as ligas Al-Si-Mg (356.0 e 357.0) solidificadas em coquilha.

\begin{tabular}{c|c|c|c|c|c}
\multicolumn{2}{c|}{ Tabela 2: Propriedades mecânicas mínimas para as ligas Al-Si-Mg (356.0 e 357.0) solidificadas em coquilha. } \\
\hline Liga & $\begin{array}{c}\text { Tratamento Tér- } \\
\text { mico }\end{array}$ & $\begin{array}{c}\text { Limite de Resistência } \\
\text { à Tração (MPa) }\end{array}$ & $\begin{array}{c}\text { Limite de Escoamen- } \\
\text { to (MPa) }\end{array}$ & $\begin{array}{c}\text { Alongamento } \\
\text { máximo (\%) }\end{array}$ & $\begin{array}{c}\text { Dureza } \\
\text { Brinell }\end{array}$ \\
\hline 356.0 & T6 & 228 & 152 & 3,0 & 85 \\
\hline 357.0 & T6 & 310 & 248 & 3,0 & 100 \\
\hline
\end{tabular}

Fonte: Standart Specification for Aluminum - Alloy Permanent Mold Castings, B 108 - 06 [6].

A aplicação de tratamentos térmicos modifica as características microestruturais e melhoraram as propriedades tecnológicas das ligas Al-Si-Mg. O tratamento térmico de endurecimento por precipitação é o método mais comum para aumentar a resistência das ligas de Al-Si-Mg. Segundo MANENTE e TIMELLI [7], o tratamento térmico compreende três fases: solubilização, resfriamento rápido e envelhecimento artificial. Segundo OLIVEIRA e ROCHA [8], normalmente é especificado 6 horas de solubilização em $540^{\circ} \mathrm{C}$ para a liga 356.0, seguido de resfriamento rápido em água e, na etapa de envelhecimento artificial, utiliza-se geralmente temperaturas que variam entre $175^{\circ} \mathrm{C}$ a $240^{\circ} \mathrm{C}$ durante 7 a 9 horas.

As propriedades mecânicas das ligas fundidas de alumínio também são significativamente dependentes de características microestruturais. Os espaçamentos dendríticos são alguns parâmetros que controlam as propriedades mecânicas das peças fundidas [9]. A velocidade de resfriamento durante a solidificação do metal líquido afeta o espaçamento dos braços dendríticos secundários [10].

De acordo com PUPARATTANAPONG e LIMMANEEVICHITR [11], nas peças fundidas de ligas de alumínio a porosidade é o defeito que ocorre mais frequentemente. A presença de porosidade é acompanhada por um decréscimo nas propriedades mecânicas, isto é, tensão de ruptura, ductilidade e resistência à fadiga, etc. A porosidade é considerada a principal causa de rejeição das peças fundidas nas aplicações industriais.

Nesse sentido, o presente estudo objetiva analisar a influência do percentual de porosidade nas propriedades mecânicas de limite de resistência à tração, deformação específica e dureza em ligas de alumínio, silício e magnésio fundidas e tratadas termicamente. 


\section{MATERIAIS E MÉTODOS}

Primeiramente foi obtida uma liga do sistema $\mathrm{Al}-\mathrm{Si}-\mathrm{Mg}$ com composição química semelhante à liga comercial 356.0. Essa liga foi produzida a partir da fusão de alumínio primário, alumínio-silício (12\% de silício) e magnésio metálico.

Após obtenção da liga, foi realizada a análise térmica para obtenção das temperaturas Liquidus $\left(\mathrm{T}_{\mathrm{L}}\right)$ e Solidus $\left(\mathrm{T}_{\mathrm{S}}\right)$. Para tanto, a liga foi novamente fundida em um forno tipo poço e cadinho de carbeto de silício, o metal líquido em uma temperatura de $700^{\circ} \mathrm{C}$ foi vazado em um molde cilíndrico de areia-shell, com cerca de $30 \mathrm{~mm}$ de diâmetro e $60 \mathrm{~mm}$ de altura, contendo em seu centro um termopar do tipo K (Cromel-Alumel) com isolação mineral e protegido por uma bainha de aço inox 310 , de diâmetro igual a $1,5 \mathrm{~mm}$. O termopar foi conectado em um sistema de aquisição de dados modelo CAD 12/36 (conversor analógico digital) com um módulo condicionador de sinal analógico MSC 1000. O software utilizado para o registro dos dados foi o AqDados v.5.06. A frequência de aquisição de dados foi de quatro leituras por segundo.

Para determinar as taxas de resfriamento $(R)$, analisou-se de forma detalhada as curvas de resfriamento obtidas durante solidificação de um lingote da liga base. Este lingote foi obtido com a fusão da liga em um forno tipo poço e cadinho de carbeto de silício. A temperatura do metal líquido no forno foi mantida entre $720^{\circ} \mathrm{C} \mathrm{e}$ $730^{\circ} \mathrm{C}$. A temperatura de vazamento foi de $700^{\circ} \mathrm{C}$. O metal líquido foi vazado em uma lingoteira, de aço inoxidável AISI 304, com diâmetro interno de $44 \mathrm{~mm}$, altura de $180 \mathrm{~mm}$ e espessura de parede de $13 \mathrm{~mm}$. A lingoteira foi pré-aquecida a $400^{\circ} \mathrm{C}$ e a solidificação ocorreu de forma natural.

As curvas de resfriamento durante a solidificação do lingote forma obtidas, com termopares para registro das temperaturas durante a evolução da solidificação, sendo que foram utilizados cinco termopares posicionados na lingoteira, conforme representação na Figura 1. Os termopares T1, T2, T3, T4 e T5 foram posicionados respectivamente a 5, 20, 40, 60 e $80 \mathrm{~mm}$ da base da lingoteira. Os termopares utilizados foram do tipo K, com bainha em aço inoxidável SAE 304 de $1 \mathrm{~m}$ de comprimento e diâmetro de 1,6 mm.
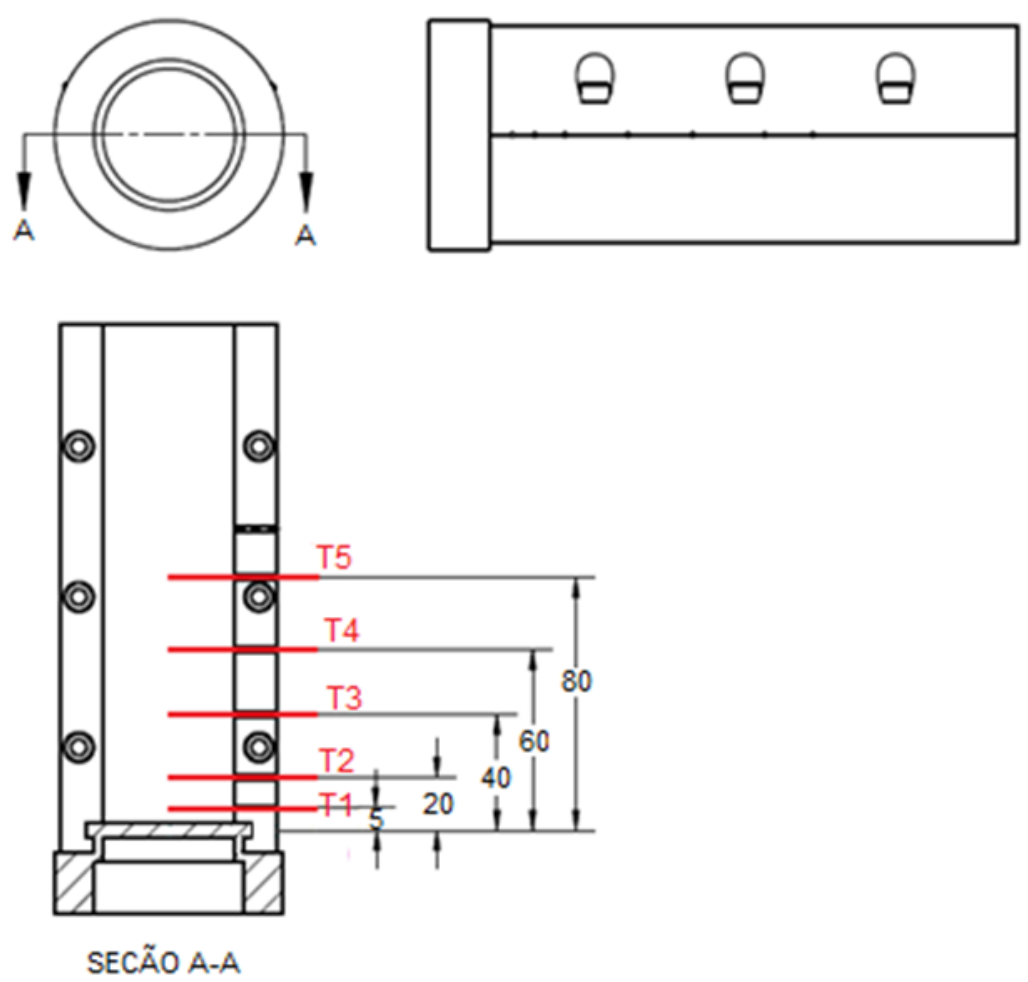

Figura 1: Posição dos termopares na lingoteira (medidas em milímetros).

Através desse sistema montado foi feito o registro das leituras obtidas nos termopares e, assim, o perfil térmico concernente à solidificação natural da liga de Al-Si-Mg foi construído. Com as curvas de resfriamento, foram obtidas as taxas de resfriamento, baseando-se em GOMES [12], onde as taxas de resfriamento $(R=\Delta T / \Delta t)$ à frente da isoterma Liquidus podem ser calculadas através da derivada da curva ajustada na regi- 
ão próxima ao instante de tempo onde o perfil térmico atinge a Temperatura Liquidus.

Foram produzidos 8 lingotes. Para isso, manteve-se as temperaturas do metal líquido no forno, de vazamento e temperatura da lingoteira semelhantes às utilizadas para obtenção das curvas de resfriamento. Metade dos lingotes foram submetidos a processo de desgaseificação. Durante a fusão, o metal líquido foi desgaseificado com 15 gramas de pastilhas de hexacloroetano $\left(\mathrm{C}_{2} \mathrm{Cl}_{6}\right)$, com auxílio de sino de imersão e tempo de espera de 10 minutos. Os lingotes restantes não sofreram processo de desgaseificação. Durante a fusão, as ferramentas como sino e lanças utilizadas foram de aço inoxidável AISI 304.

A partir dos lingotes produzidos foram retiradas amostras da seção transversal circular utilizadas para a análise do percentual de porosidade, do espaçamento dendrítico secundário e determinação das propriedades mecânicas. As amostras foram obtidas realizando cortes transversais ao longo do comprimento dos lingotes. As amostras foram denominadas de P1, P2, P3, P4, P5 e foram obtidas a uma distância da base da lingoteira de $5 \mathrm{~mm}, 20 \mathrm{~mm}, 40 \mathrm{~mm}, 60 \mathrm{~mm}$ e $80 \mathrm{~mm}$, respectivamente, conforme observa-se na Figura 2.

Todas as amostras obtidas foram submetidas ao tratamento térmico de envelhecimento por precipitação - T6. A etapa de solubilização foi feita na temperatura de $540^{\circ} \mathrm{C} \pm 10^{\circ} \mathrm{C}$, durante 6 horas, seguido de resfriamento em água morna na temperatura entre $60^{\circ} \mathrm{C} \pm 5^{\circ} \mathrm{C}$. O envelhecimento artificial foi realizado na temperatura de $180^{\circ} \mathrm{C}$, durante 8 horas.
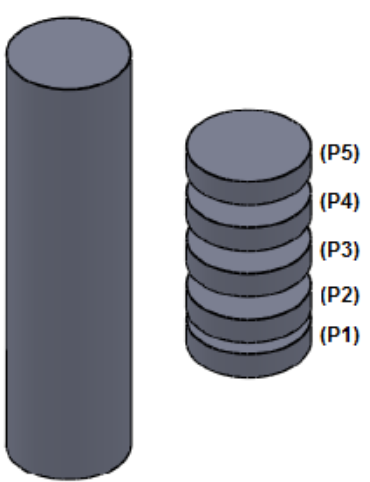

(a)

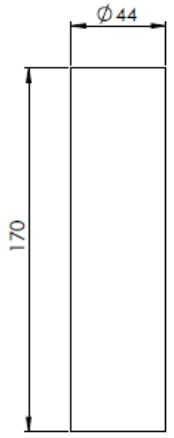

(b)

Figura 2: Disposição das amostras ao longo do lingote: (a) vista tridimensional, (b) vista ortogonal com as cotas em milímetros.

$\mathrm{Na}$ análise da porosidade foram utilizadas as amostras da seção transversal circular. Essa análise antecedeu os demais procedimentos, e foram realizadas 4 medidas para cada condição (sem desgaseificação e desgaseificada) e posição em análise, sendo que, ao final, obteve-se a média dos valores e o intervalo de dispersão.

Para medir a porosidade, usou-se a técnica denominada picnometria, que é um processo de comparação das massas específicas relativas do sólido e do líquido (água destilada), onde foi possível medir a massa específica aparente das amostras. O método picnométrico empregado baseia-se na norma ASTM B 311-93 [13] (reaprovada em 2002). Após a determinação da massa específica aparente $\left(\rho_{A}\right)$ das amostras, foi possível estimar a porosidade, utilizando a Eq. (1):

$\%$ Poros $=\left[\left(\rho_{T}-\rho_{A}\right) / \rho_{T}\right] * 100$

onde: $\rho_{T}$ : massa específica teórica das amostras.

Já, para determinar a massa específica teórica das amostras, foi utilizada a porcentagem em peso dos elementos químicos obtidos na caracterização química realizada em Espectrômetro de Emissão Óptica. Com a porcentagem em peso de cada elemento constituinte das ligas, buscou-se na bibliografia [14] a massa específica de cada elemento e calculou-se a massa específica teóricas das ligas em estudo.

Para investigar as medidas de espaçamentos dendríticos secundários, tornou-se necessário a realização de 
análise micrográfica. Na realização da análise da micrografia, utilizou-se amostras referentes a dois lingotes (nas condições com e sem desgaseificação) sendo que de cada amostra circular, referente a cada posição em análise no lingote, foi retirada uma amostra de seção quadrada de aproximadamente $15 \times 15 \mathrm{~mm}$, como observa-se na Figura 3(a). A medição dos espaçamentos dendríticos secundários foi realizada na seção transversal em destaque.

As amostras foram lixadas e polidas. Para revelação da micrografia realizou-se ataque com solução de 5\% de $\mathrm{HF}(95 \mathrm{ml}$ de $\mathrm{H} 2 \mathrm{O}+5 \mathrm{ml}$ de HF). As amostras foram então observadas e examinadas em um microscópio óptico. Já os espaçamentos dos braços dendríticos secundários $\left(\lambda_{2}\right)$ foram investigados conforme procedimento proposto por MCCARTNEY e HUNT [15], que se baseia em calcular a média das distâncias entre o centro geométrico dos braços secundários adjacentes. Assim, para a medição dos espaçamentos dendríticos secundários foi obtido à distância média de quatro braços dendríticos. Foram executadas cerca de 20 medidas para cada posição em análise, sendo que, ao final, obteve-se a média dos valores e o intervalo de dispersão.

As amostras de seção transversal circular restantes, foram utilizadas para medição de dureza Brinell. E na sequência, foram retirados de cada amostra dois corpos de prova para ensaio de tração, sendo obtido no total seis corpos de prova para cada condição e posição em análise. Na Figura 3(b), observa-se nas amostras onde foram realizados os ensaios de dureza (seção transversal em destaque) e na Figura 3(c) onde foram retirados os corpos de prova para ensaio de tração. Os corpos de prova, para ensaio de tração foram obtidos com dimensões reduzidas, conforme Figura 3(d), proporcionais ao modelo padrão, conforme especificado pela norma ASTM E8M-03 [16].

A dureza foi medida por meio de um durômetro Brinell, com penetrador esférico de carbeto de tungstênio de diâmetro de $5 \mathrm{~mm}$, uma carga de $2500 \mathrm{~N}$ (250 kgf) e tempo de penetração de 20 segundos, segundo a norma ABNT NBR NM ISO 6506-1:2010 [17]. Foram realizadas três medidas em cada amostra.

Os ensaios de tração, para determinação do limite de resistência à tração (LRT) e deformação específica $(\varepsilon)$ foram executados utilizando a máquina de ensaios da marca EMIC, com capacidade de $10 \mathrm{kN}$, sistema de aquisição de dados do próprio fabricante, do modelo EEGA - 250, e uma velocidade de ensaio em torno de 4 $\mathrm{mm} / \mathrm{s}$.

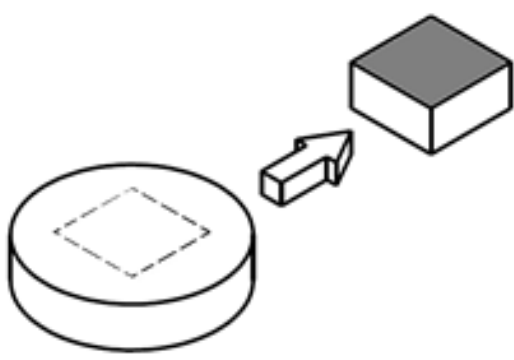

(a)

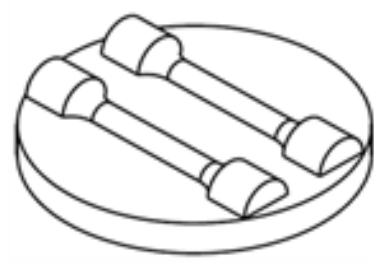

(c)

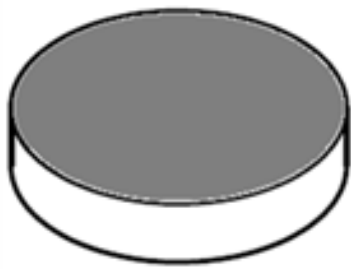

(b)

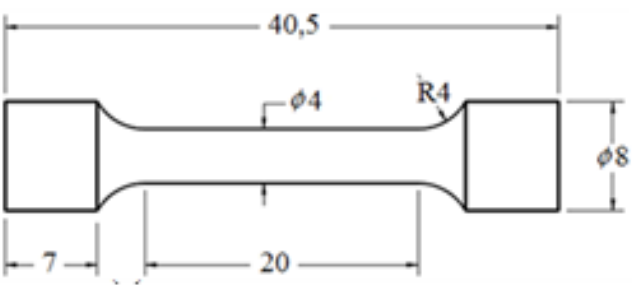

(d)

Figura 3: Esquema representativo dos corpos de prova: (a) Seção transversal das amostras onde foram realizadas as medições dos espaçamentos dendríticos secundários; (b) Amostras circulares usadas na medição da porosidade; (c) Posição dos corpos de prova de tração retirados das amostras circulares dos lingotes; (d) Dimensões em milímetros dos corpos de prova para ensaios de tração. 


\section{RESULTADOS}

Após a preparação das cargas, fusão e solidificação da liga básica, obteve-se a caracterização da composição química das mesmas por Espectroscopia de Emissão Óptica, e confirmou-se conforme a Tabela 3.

Tabela 3: Composição química média (\% em massa) da liga em estudo.

\begin{tabular}{c|c|c|c|c|c|c|c|c}
\cline { 2 - 8 } & $\mathrm{Al}$ & $\mathrm{Si}$ & $\mathrm{Fe}$ & $\mathrm{Cu}$ & $\mathrm{Mn}$ & $\mathrm{Mg}$ & $\mathrm{Zn}$ & \multicolumn{2}{c}{ Outros } \\
\hline Liga & 91,43 & $\mathbf{6 , 5 0}$ & 0,60 & 0,27 & 0,12 & $\mathbf{0 , 6 0}$ & 0,21 & 0,27 \\
\hline
\end{tabular}

Com a análise química, constatou-se que além dos elementos químicos principais $\mathrm{Al}, \mathrm{Si}$ e $\mathrm{Mg}$, o elemento químico Fe apresentou-se com teor significativo, oriundo da matéria prima e ferramentas utilizadas durante processo de fusão.

A liga obtida apresentou composição química semelhante à liga comercial 356.0, conforme mostra a Tabela 1 , mas com teores reduzidos de zinco e manganês, e sem a presença de titânio. Dessa forma, a liga em estudo pode vir a se apresentar como uma liga alternativa de menor preço que a liga comercial 356.0.

A determinação das temperaturas Liquidus $\left(T_{L}\right)$ e Solidus $\left(T_{S}\right)$ foi possível analisando as curvas de resfriamento experimentais que foram traçadas a partir das informações do termopar localizado no centro do molde de areia-shell, para a liga Al-6,5\%Si-0,6\% Mg. Essa curva de resfriamento pode ser visualizada na Figura 4, onde é possível se observar os patamares característicos das Temperaturas Liquidus e Solidus da liga, que corresponde ao início e fim da solidificação, respectivamente. Os valores determinados foram: $T_{L}=611{ }^{\circ} \mathrm{C}$ e $T_{S}=562{ }^{\circ} \mathrm{C}$.

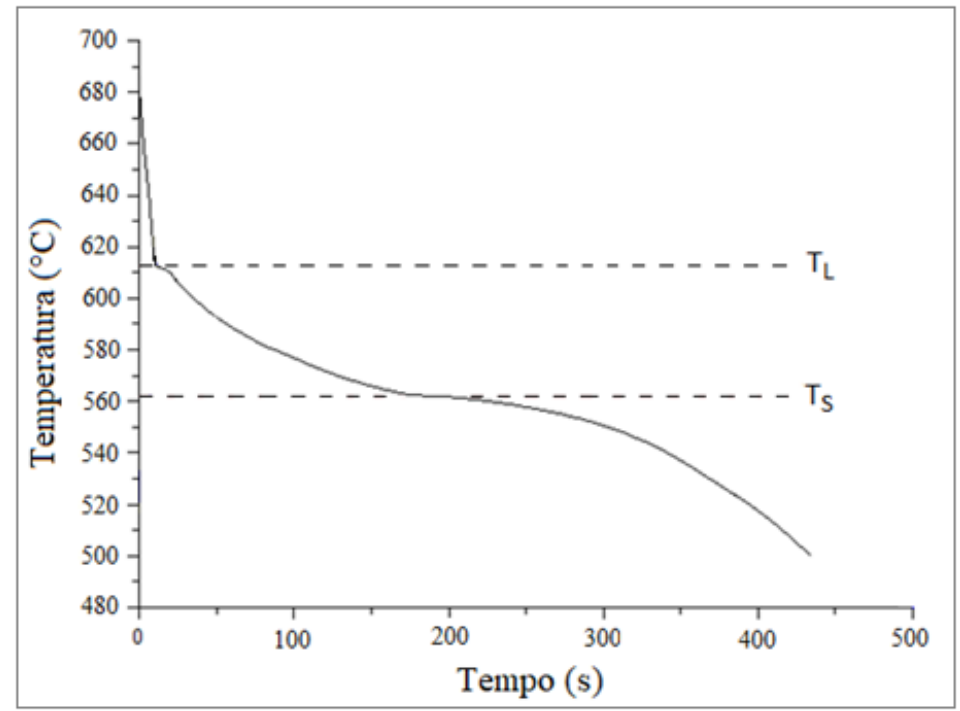

Figura 4: Curva de resfriamento com identificação das Temperaturas Liquidus $\left(T_{L}\right)$ e Solidus $\left(T_{S}\right)$.

As curvas de resfriamento experimentais para os cinco termopares inseridos no lingote durante a solidificação da liga podem ser visualizadas nas Figura 5. 


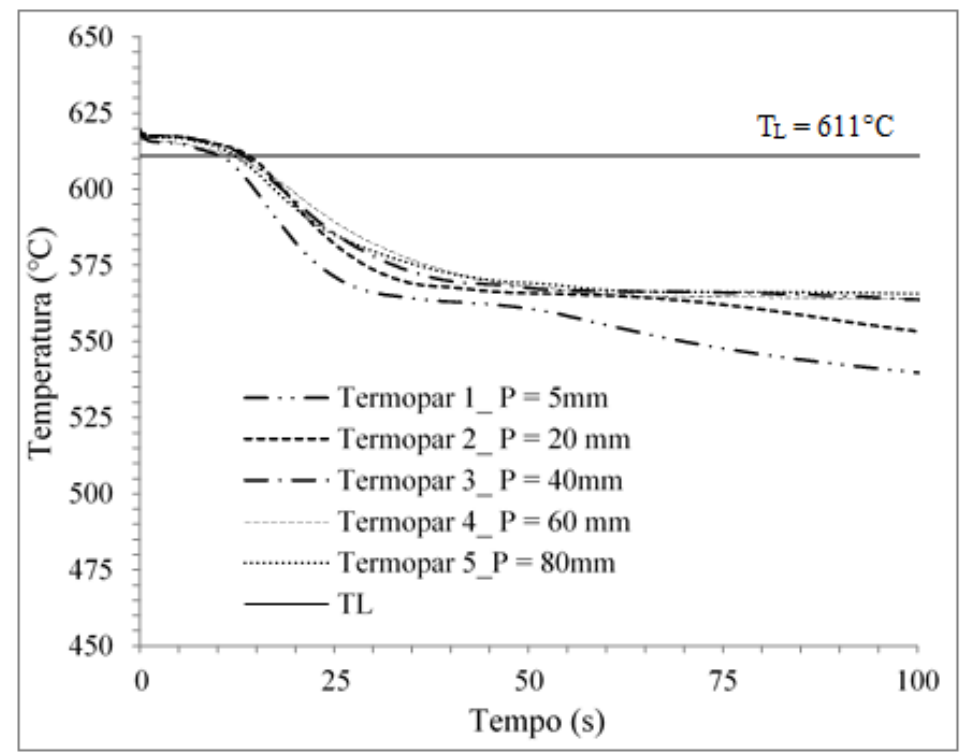

Figura 5: Curvas de resfriamento correspondentes aos termopares posicionados no interior da lingoteira.

A partir das curvas apresentadas na Figura 5 foram realizados os cálculos das taxas de resfriamento, e a Figura 6 apresenta gráficos que confrontam os espaçamentos dos braços dendríticos secundários $\left(\lambda_{2}\right)$ e as taxas de resfriamento $(R)$ com as diferentes posições em análise nos lingotes, sendo possível notar uma pequena variação na taxa de resfriamento apresentada entre as posições em análise. Durante a solidificação, segundo PATAKHAM et al. [18], a taxa de resfriamento é a variável térmica de maior influência nas variações dos espaçamentos dendríticos secundários. Segundo DONG et al. [19], os espaçamentos dos braços dendríticos secundários apresentam influência nas propriedades mecânicas das ligas de alumínio. Sendo assim, é possível concluir que durante o processo de solidificação, devido à taxa de resfriamento apresentar uma variação muito pequena, os espaçamentos dos braços dendríticos secundários, nas amostras ao longo do lingote, apresentaram pequenas variações que se espera não influenciar na variação das propriedades mecânica das ligas em estudo.

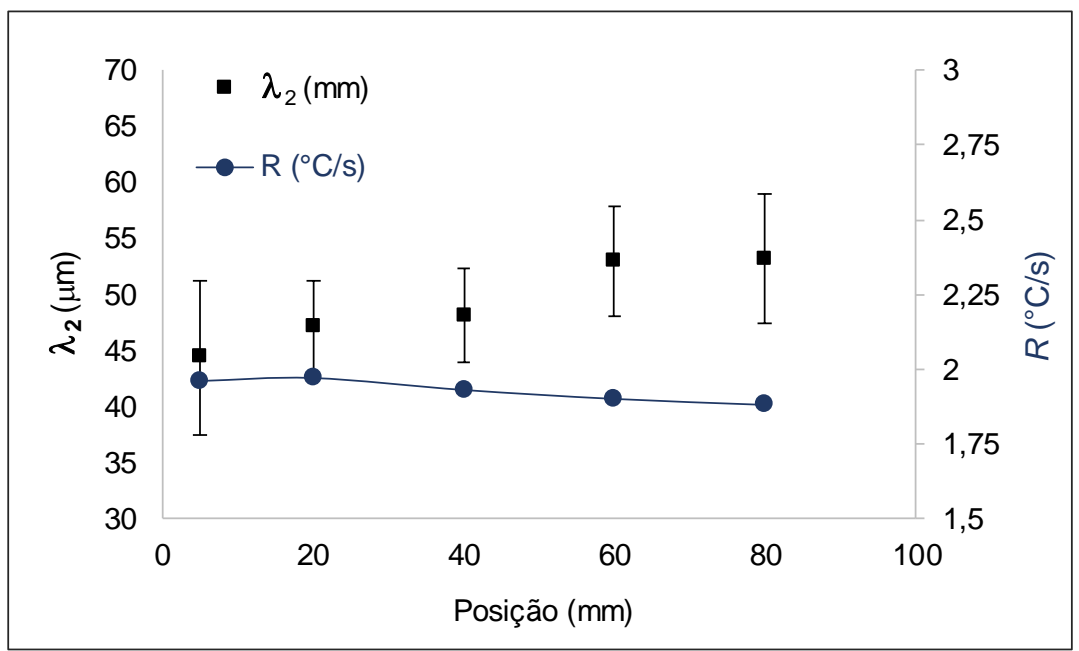

Figura 6: Espaçamentos dos braços dendríticos secundários e taxas de resfriamento (R) em função da posição ao longo do lingote.

Os dados obtidos sobre o percentual volumétrico de porosidade possibilitaram gerar gráficos que apresentam a evolução do percentual de porosidade para a liga em função das diferentes condições e posições em análise. A Figura 7 apresenta uma comparação entre os resultados experimentais da fração de poros com a posição no lingote em relação à base da lingoteira, para a liga sem desgaseificação e desgaseificada. 


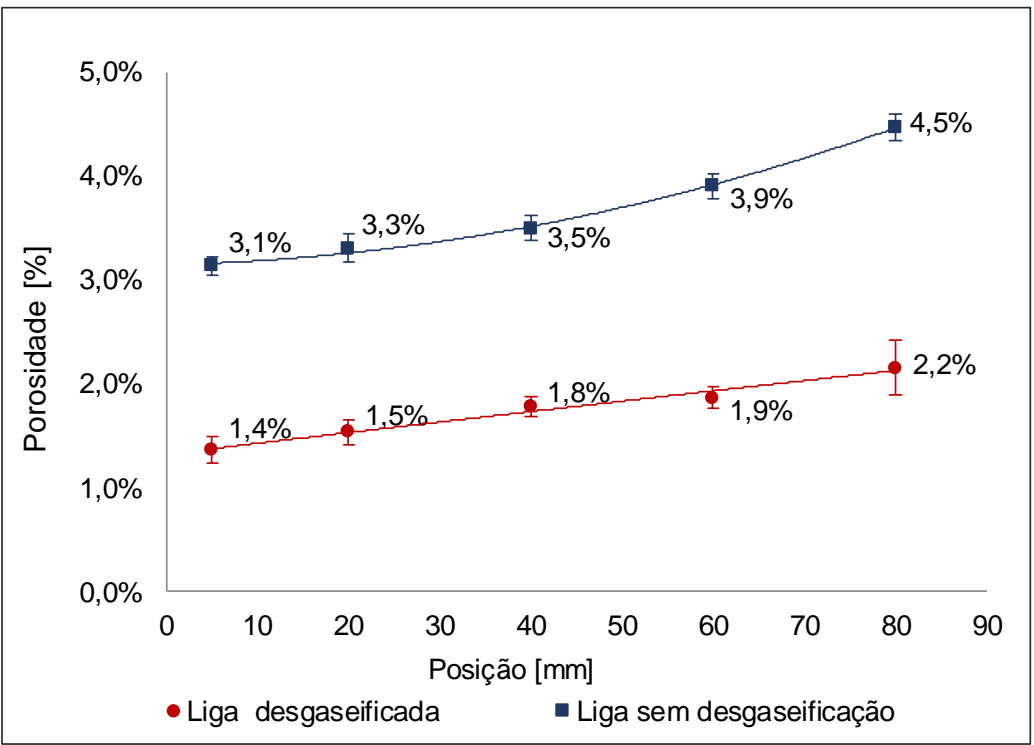

Figura 7: Fração de poros em função da posição em relação à interface metal/molde.

A Figura 7, permite observar que o processo de desgaseificação com pastilhas de hexacloroetano reduziu significativamente o percentual volumétrico de porosidade em todas as posições analisadas. Cabe salientar que as amostras P1 (retirada de uma posição à $5 \mathrm{~mm}$ da base da lingoteira), após processo de desgaseificação, apresentaram o menor percentual volumétrico de porosidade, cerca de 1,37\% em volume, que é considerado elevado por GOMES [12]. O nível de porosidade em ligas fundidas de alumínio deve ser menor que $0,5 \%$ em volume, pois valores mais elevados podem resultar em propriedades mecânicas inferiores.

Segundo KUCHARCIK et al. [20], os parâmetros de fusão e solidificação influenciam na formação de porosidade em ligas de alumínio, mas isso não permite explicar a maior presença de porosidade, já que fatores como taxa de resfriamento e temperatura de fusão se mantiveram semelhantes nos processos de fusão e solidificação de ambas as ligas. MOUSTAFA [21] indica que a presença do ferro facilita a formação de porosidade em ligas alumínio e, assim, a liga analisada, por apresentar um teor elevado de ferro (0,6\% de ferro), apresenta uma tendência para formação de intermetálicos de ferro $\mathrm{Al}_{5} \mathrm{FeSi}$ (forma de agulhas) durante a solidificação que impedem que o metal líquido possa preencher os espaços entre as agulhas ramificadas, gerando a nucleação de poros.

A variação do percentual de porosidade em função da posição das amostras em relação à base da lingoteira, em ambas as condições, é devido à presença do gás hidrogênio no alumínio líquido. Durante a solidificação, na medida em que a viscosidade da massa líquida diminui, devido à queda de temperatura, fica mais difícil a fuga desses gases, que ficam retidos em maiores proporções nas proximidades da superfície dos lingotes, na forma de bolhas, resultando na presença de maior porosidade nas amostras retiradas de posições mais distantes da base da lingoteira.

Os dados de dureza das amostras de seção transversal circular referentes às condições e posições em análise podem ser visualizados na Figura 8 . 


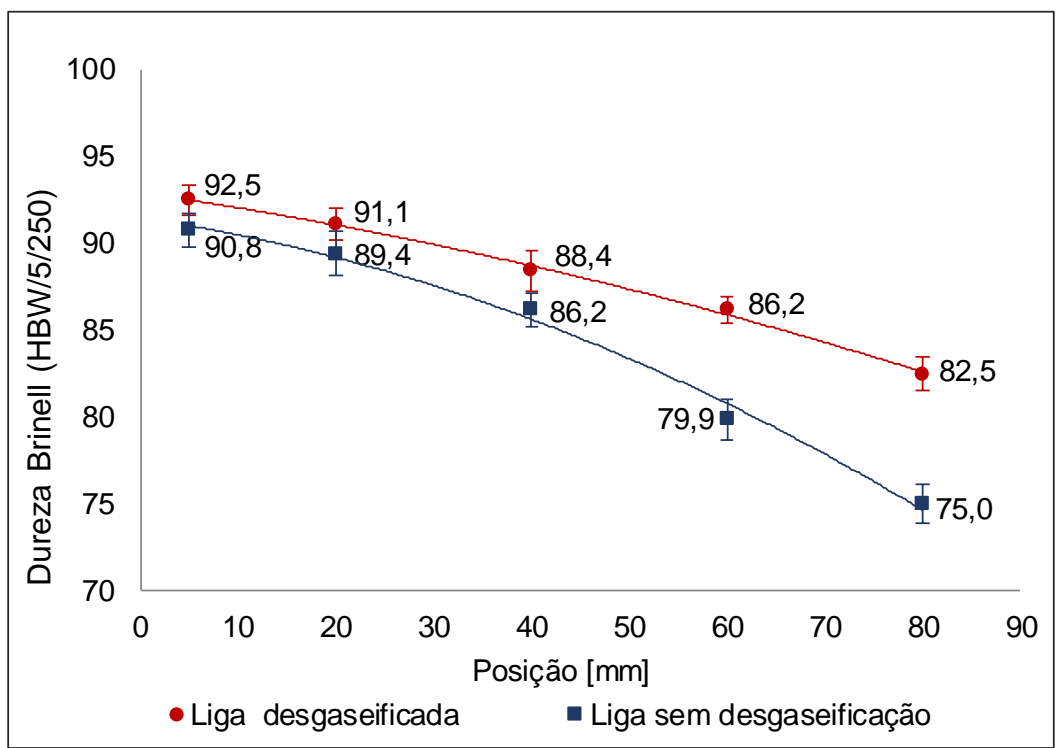

Figura 8: Dureza Brinell obtida nas diferentes posições em análise dos lingotes da liga Al-6,5\% Si-0,6\% Mg.

A análise da Figura 8 possibilita observar que as amostras desgaseificadas, em qualquer posição, apresentam maiores valores de dureza Brinell que as amostras sem desgaseificação. Com o processo de desgaseificação dos lingotes, com pastilhas de hexacloroetano, o percentual volumétrico de porosidade reduziu aproximadamente $57 \%$, em todas as posições dos lingotes. Assim, a redução do percentual de poros aumenta a resistência do material e gera maiores valores na dureza. A maior dureza foi encontrada na amostra P1, retirada da posição mais próxima da base da lingoteira $(5 \mathrm{~mm})$, onde o percentual de porosidade é menor, atingindo o valor de dureza de 92,5 HBW/5/250.

Os valores de limite de resistência à tração e deformação específica dos corpos de prova retirados das amostras foram obtidos, através dos ensaios de tração, em relação às diferentes posições a partir da base da lingoteira, e podem ser visualizados nas Figura 9 e Figura 10, respectivamente.

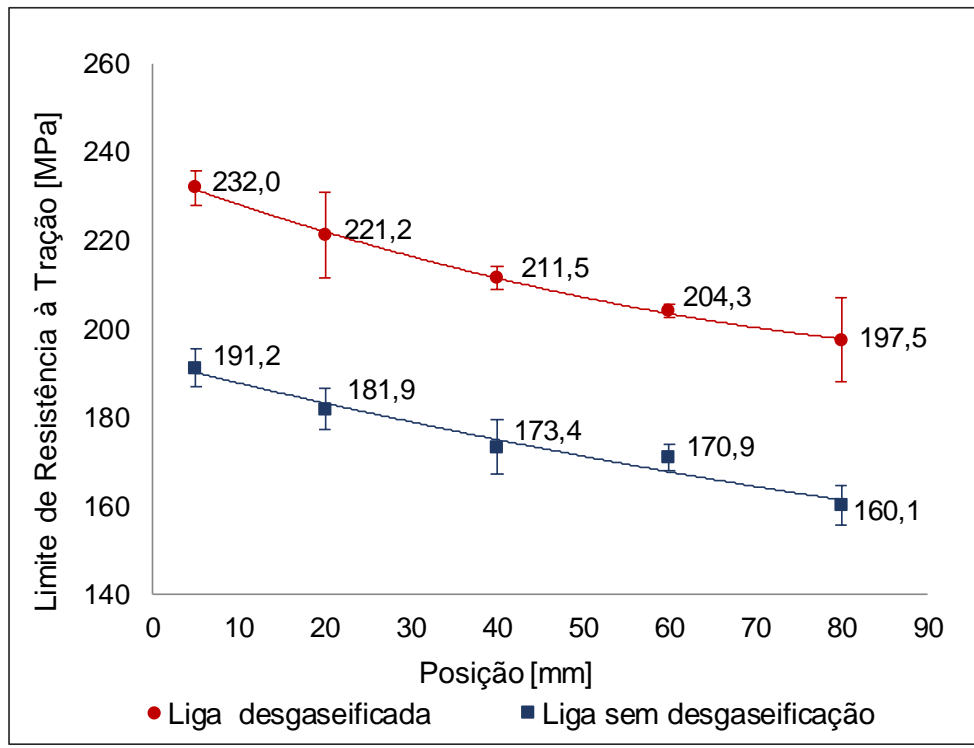

Figura 9: Limite de resistência à tração obtida nas diferentes posições dos lingotes da liga Al-6,5\% Si-0,6\%Mg. 


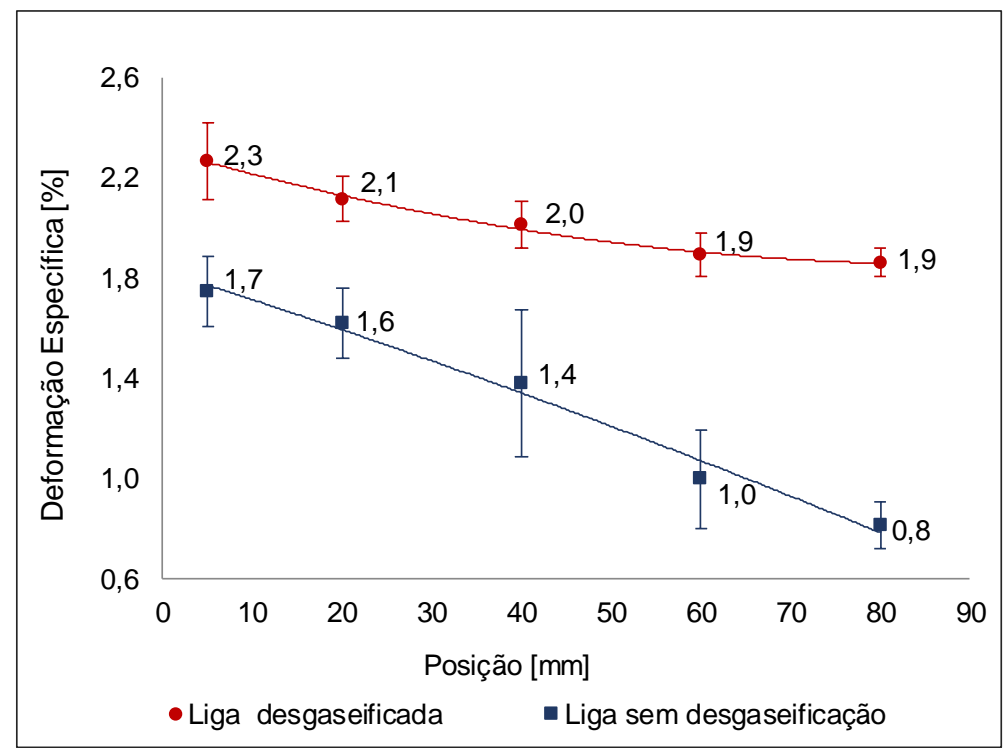

Figura 10: Deformação específica obtida nas diferentes posições dos lingotes da liga Al-6,5\% Si-0,6\% Mg.

A análise das Figuras 9 e 10 permite observar que as amostras da liga (Al-6,5\%Si-0,6\% Mg) desgaseificadas apresentam maiores limites de resistência à tração e maiores deformações específica do que as amostras sem tratamento de desgaseificação, e isso é devido ao fato de que o processo de desgaseificação reduziu significativamente o percentual volumétrico de porosidade, conforme descrito anteriormente. Aliado a isso, também se observou que as amostras retiradas de posições mais próximas da base da lingoteira apresentaram os melhores desempenhos de resistência à tração e ductilidade, em função de menor percentual de porosidade.

Com os dados obtidos foi possível construir gráficos que relacionam as propriedades mecânicas com o percentual de porosidade. Nas Figuras 11, 12 e 13 há gráficos do limite de resistência à tração em função da porosidade, deformação específica em função da porosidade e dureza em função da porosidade, respectivamente, além das as curvas de ajuste dos valores experimentais obtidos e as funções lineares geradas. A qualidade da concordância entre resultados experimentais e as equações geradas (grau de ajuste) foi apresentado em termos do coeficiente de correlação $\mathrm{R}^{2}$ do método dos mínimos quadrados.

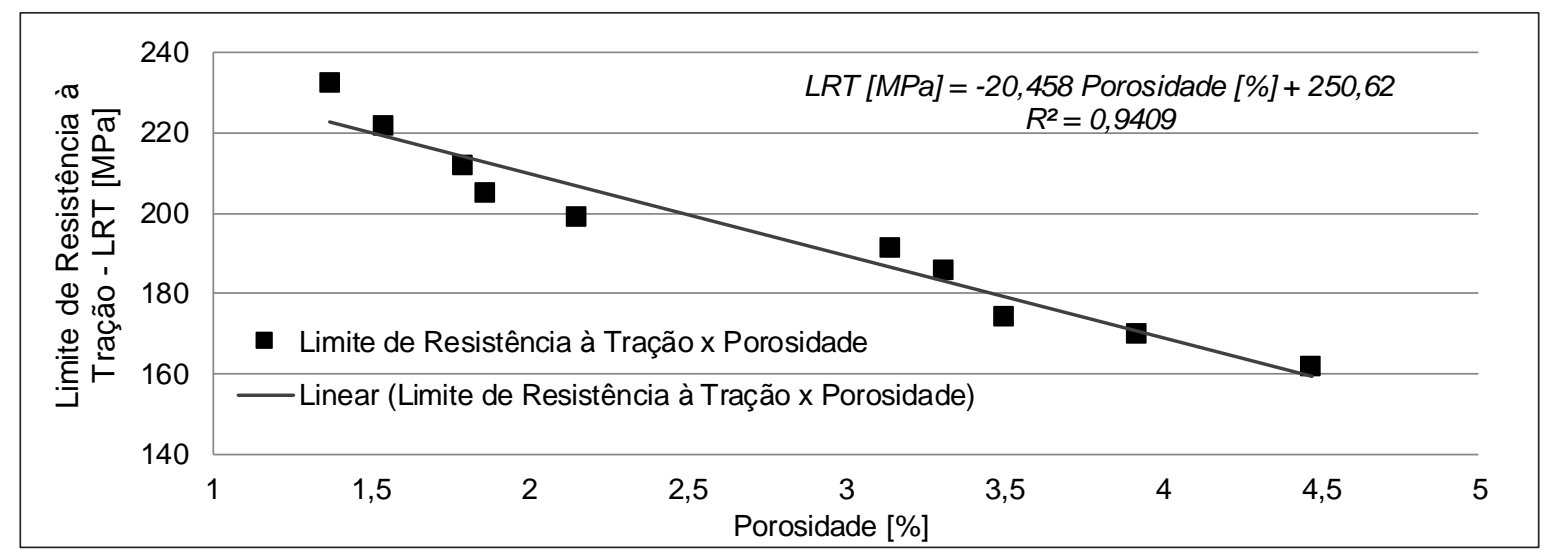

Figura 11: Limite de Resistência à Tração x Percentual volumétrico de porosidade. 


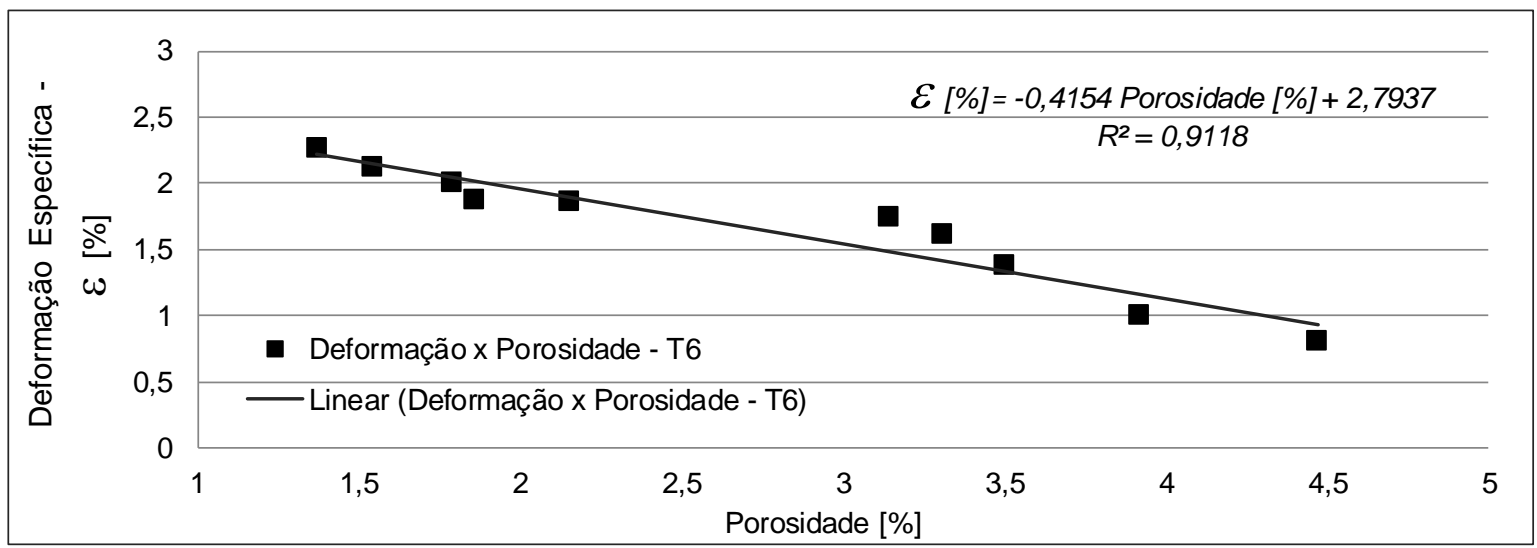

Figura 12: Deformação Específica $x$ Percentual volumétrico de porosidade.

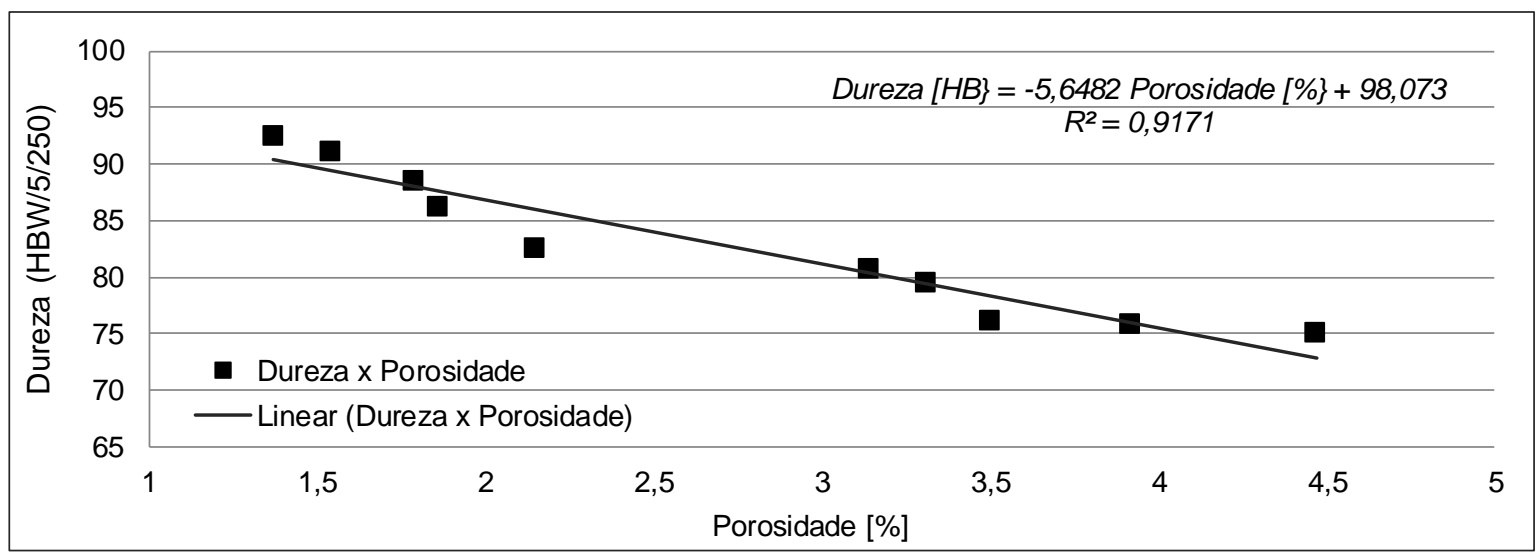

Figura 13: Dureza Brinell x Percentual volumétrico de porosidade.

O efeito negativo da porosidade no limite de resistência a tração, na deformação específica e na dureza é evidente. Aplicando as equações encontradas a partir de regressão linear, é possível estimar que as amostras da liga (Al-6,5\% Si-0,6\% Mg), fundidas, solidificadas e tratadas termicamente nas mesmas condições adotadas neste artigo, livres da presença de porosidade, apresentariam um limite de resistência à tração de aproximadamente $251 \mathrm{MPa}$, uma deformação específica próxima de 2,8\% e uma dureza em torno de $98 \mathrm{HB}$. Mas, como a porosidade é um defeito extremamente difícil de ser eliminado por completo nas ligas de alumínio fundidas, a análise dos gráficos e as equações permite observar que a cada $1 \%$ de porosidade volumétrica são esperadas quedas em torno de $10 \%$ no limite de resistência à tração, em torno de $18 \%$ na deformação específica e de aproximadamente $5 \%$ na dureza.

\section{CONCLUSÕES}

A partir dos resultados as seguintes conclusões foram obtidas:

- Em relação às propriedades mecânicas, as amostras da liga produzida (como menor porosidade), após tratamento térmico, apresentaram limites de resistência à tração e durezas superiores aos da liga comercial 356.0 T6, conforme especificado pela norma ASTM B 108 [6].

- Durante o processo de solidificação da liga, devido às condições de solidificação se manterem semelhantes, as variáveis de solidificação ao longo dos lingotes se mostraram praticamente constantes, evitando que as mesmas apresentassem influências significativas nas propriedades mecânicas da liga.

- Em relação à porosidade, nos lingotes produzidos houve presença de maior porosidade nas amostras retiradas de posições mais distantes da base da lingoteira, enquanto o processo de desgaseificação reduziu o percentual volumétrico de porosidade em todas as amostras.

- Durante a análise das propriedades mecânicas da liga (Al-6,5\% Si-0,6\%Mg) foi observado que as amostras 
na condição desgaseificada apresentaram os melhores resultados para as propriedades mecânicas analisadas, ao passo que, para as amostras retiradas da posição mais próxima da base da lingoteira, onde o efeito negativo da porosidade é menor, foram obtidos o maior limite de resistência à tração (175,5 MPa), a maior deformação específica $(2,3 \%)$ e a maior dureza Brinell $(70,7 \mathrm{HB})$.

- Em relação à influência da porosidade nas propriedades mecânicas da Liga (Al-6,5\% Si-0,6\%Mg), tratada termicamente, foi confirmado o efeito negativo da porosidade nas propriedades em análise, através de modelos matemáticos encontrados a partir de dados obtidos sobre o comportamento de diversas amostras da liga submetidas a ensaios de tração e de dureza.

\section{BIBLIOGRAFIA}

[1] GOPIKRISHNA, S., BINU, C. Y., "Study of effects of T6 heat treatment on grain refined A319 alloy with magnesium and strontium addition", International Journal on Theoretical and Applied Research in Mechanical Engineering, v.2, pp. 59-62, 2013.

[2] SERRANO-MUNOZ, I, BUFFIERE, J. Y, VERDU, C., et al., "Influence of surface and internal casting defects on the fatigue behaviour of A357-T6 cast aluminium alloy". International Journal of Fatigue, Volume 82, Part 3, pp. 361-370, 2016.

[3] HOSSAIN, A., KURNY, A. S. W., "Effect of ageing temperature on the mechanical properties of Al-6Si$0.5 \mathrm{Mg}$ cast alloys with $\mathrm{Cu}$ additions treated by $\mathrm{T} 6$ heat treatment", Universal Journal of Materials Science, v.1, n.1, pp. 1-5, 2013.

[4] KAEEL, A. J., "Study the effect of solution treatment on mechanical properties of Al-7\% $1 \mathrm{Si}-0.3 \% \mathrm{Mg}$ alloy", Natural and Applied Sciences, v. 4 n. 4, 2013.

[5] ASM - Castings, ASTM International, v. 15, 9th, Edition Metals Handbook, 2002.

[6] ASTM - American Society for Testing Materials. ASTM B 108 - 06 - Standart Specification for Aluminum - Alloy Permanent Mold Castings. In Annual Book of ASTM, 2006.

[7] MANENTE, A., TIMELLI, G., "Optimizing the heat treatment process of cast aluminium alloys", INTECH Open Access Publisher, n. 9, pp. 197-220, 2011.

[8] OLIVEIRA, R. O. M., ROCHA, O. F. L. "Tratamento térmico de precipitação-T6 aplicado em roda de liga leve de motocicleta", Holos, v. 5, pp. 372-382, 2014.

[9] SHABANI, M. O., MAZAHERY, A., "Prediction of mechanical properties of cast a356 alloy as a function of microstructure and cooling rate", Archives of Metallurgy and Materials, v. 56, pp. 671-675, 2011.

[10] DOBRZANSKI, L. A., BOREK, W., MANIARA, R., "Influence of the crystallization condition on Al$\mathrm{Si}-\mathrm{Cu}$ casting alloys structure", Journal of Achievements in Materials and Manufacturing Engineering, v. 18, n. 1-2, pp. 211-214, 2006.

[11] PUPARATTANAPONG, K., LIMMANEEVICHITR, C., "Effect of scandium on porosity formation in Al-6Si-0.3Mg alloys", The Indian Institute of Metals - IIM, pp. 1-8, 2016.

[12] GOMES, L. G., "Microestrutura Dendrítica, Macrossegração e Mocroporosidade na Solidificação de Ligas Ternárias Al-Si-Cu", Tese de D.Sc., Universidade Estadual de Campinas , São Paulo, Universidade Estadual de Campinas. Campinas/São Paulo, 2012.

[13] American Society for Testing and Materials, Philadelphia, ASTM Standart B311-93, "Test Method for Density Determination for Powder Metallurgy (P/M) Materials Containing Less Than Two Percenty Porosity", PA.

[14] ASHBY, M. F. E JONES, D. R. H.,Engineering Materials 1: An Introduction to Properties, Applications and Design, 3 ed., Butterworh Heinemann, 2005.

[15] MCCARTNEY D. G., HUNT J. D. "Measurements of cells and primary dendrite arm spacing in directionally solidified aluminium alloys", Acta Metallurgica, v.29, pp. 1851-1863, 1981.

[16] ASTM E 8M - 04, 2004."Standard Test Methods for Tension Testing of Metallic Materials". ASTM International, West Conshohocken, PA.

[17] ABNT NBR NM ISO 6506-1:2010. "Materiais metálicos - Ensaio de dureza Brinell”. Associação Brasileira de Normas Técnicas.

[18] PATAKHAM, U., KAJORNCHAIYAKUL, J., LIMMANEEVICHITR, C., "Modification mechanism of eutectic silicon in $\mathrm{Al}-6 \mathrm{Si}-0.3 \mathrm{Mg}$ alloy with scandium", Journal of Alloys and Compounds, v. 575, p. 273- 
$284,2013$.

[19] DONG, Q-Z, CHOI, Y-S, HONG, J-H., et al., "Prediction of mechanical properties of Al alloys with change of cooling rate", Overseas Foundry, v.9, n.4, pp. 671-675, 2012.

[20] KUCHARCIK, L, BRUNA, M., SLADEK, A., "Influence of Chemical Composition on Porosity in Aluminum Alloy", Archives of Foundry Engineering, v.14, n. 2, pp. 5-8, 2014.

[21] MOUSTAFA, M.A., "Effect of iron content on the formation of $\beta$-Al5FeSi and porosity in Al-Si eutectic alloys”, Journal of Materials Processing Technology, v.209, pp. 605-610, 2009.

\section{ORCID}

Albino Moura Guterres

Carlos Alexandre dos Santos

Claudio André Lopes Oliveira https://orcid.org/0000-0002-8192-2351

https://orcid.org/0000-0001-5921-2604

https://orcid.org/0000-0001-5167-3721 